\title{
Assessing preferences regarding centralized and decentralized water infrastructure in post-earthquake Leogane, Haiti
}

\author{
Heather C Galada ${ }^{1 *}$, Franco A Montalto ${ }^{1 \dagger}$, Patrick L Gurian ${ }^{1 \dagger}$, Mimi Sheller ${ }^{2 \dagger}$, Tibebu B Ayalew ${ }^{1 \dagger}$
} and Stephen O'Connor ${ }^{3+}$

\begin{abstract}
Background: Though the benefits of centralized water systems (e.g. improved publichealth, environmental protection, streamlined operations, economy of scale, reliability) are well known, these systems are not always feasible or appropriate. In developing world settings there has been growing interest by infrastructure experts,researchers, and international lending institutions in decentralized means of improving access to drinking water. While decentralized water systems with independent components may be less vulnerable to systemic failures, hazards, and extreme environmental events, centralized water systems are often associated with a higher quality of life. This study investigates stakeholder preferences regarding water infrastructure issues in Leogane, Haiti (population 300,000), a town situated at the epicenter of the January 2010 earthquake.

Methods: The methodology included a paper survey, semi-structured interviews, and a participatory workshop.

Results: While most of the study participants relied on decentralized water sources prior to the earthquake, a majority also expressed a preference for a centralized water system going forward. However, the study participants articulated an integrated vision for the future of local water management. Study participants indicated an interest in alternative decentralized solutions, for example featuring artesian wells with homewater treatment, and saw linkages between water supply decisions and local environmental protection, agriculture, and deforestation.
\end{abstract}

Conclusions: These results are discussed within the context of sustainable infrastructure reconstruction efforts in Haiti, specifically as an example of how local preferences can be integrated into the visioning of infrastructure design.

Keywords: Water infrastructure; Post-disaster; Public preferences; Sustainability; Resilience

\section{Background}

Though progress is being made, approximately $11 \%$ of the world's population (783 million people) does not have access to safe drinking water (UN 2012). Sustainable water infrastructure systems are needed that equitably and costeffectively provide drinking water to users while minimizing negative impacts on ecosystems. To effectively address human needs, the design and layout of these critical infrastructure systems must be customized to reflect local customs and preferences. All three sets of considerations

\footnotetext{
* Correspondence: hgalada@gmail.com

${ }^{\dagger}$ Equal contributors

'Department of Civil, Architectural and Environmental Engineering, Drexel

University, 3141 Chestnut Street, 19104 Philadelphia, PA, USA

Full list of author information is available at the end of the article
}

(economic, ecological, and social) must be simultaneously considered in the planning and design of sustainable water systems.

Though such infrastructure decisions can be made solely based on "expert knowledge," more robust designs are developed with intensive stakeholder input. The participation of local stakeholders in the conceptualization and design of infrastructure projects acknowledges the "stake" that the intended beneficiaries have in the project's outcome, and increases the likelihood that these investments will directly address local needs. Though stakeholder participation is now widely recognized as essential in both developed and developing nation contexts (Greenwood and Levin, 1998), it is particularly important after disasters, when there are 
often strong countervailing forces seeking quick-fixes (Kennedy et al. 2008; Lawther 2009; Leon et al. 2009).

This study investigates stakeholder preferences regarding water infrastructure planning in Leogane, Haiti (population $\sim 300,000$ ), a town situated at the epicenter of the January 2010 earthquake, and about $30 \mathrm{~km}$ west of the capital, Port-au-Prince. The motivation for the study is the unprecedented level of aid pledged for reconstruction after the earthquake, and the opportunity it appeared to present to significantly improve access to water in Haiti. To a country that had never received more than $\$ 500$ million in foreign direct investment in any given year, a total of about $\$ 10$ billion (BBC 2010) was pledged by individual donors and the international community after the earthquake. The Reconstruction Action Plan earmarked $\$ 160$ million (or approximately $4 \%$ of its first 18 months of reconstruction expenditures) toward the goal of achieving $60 \%$ drinking water access, and $58 \%$ sanitation access in metropolitan zones.

Through interactions with stakeholders in this one city, our overall goal was to elicit local perspectives about how the reconstruction funds earmarked for water and sanitation might be most appropriately invested. We sought not to track specific investments, but rather to inform reconstruction decisions regarding water with local knowledge. In this paper, we focus on water systems, and specifically the degree to which local stakeholders expressed a preference for a centralized versus a decentralized approach to post-earthquake re-building of water systems. The present study is part of a larger planning study in which we also considered sanitation infrastructure preferences (Montalto et al., submitted), and preferences with respect to system management and ownership (Galada et al., 2013).

Before introducing the research methods, a general overview of centralized and decentralized water systems is provided, followed by a general description of the geographic and infrastructure setting in Leogane.

\section{Overview of centralized and decentralized water infrastructure options}

Centralized and decentralized approaches apply different spatial strategies, but also differ in terms of their associated costs, operation and management, latent vulnerability to hazards, and expandability potential. In many urbanized regions of the industrialized and post-industrial world, drinking water is sourced and distributed in a centralized fashion; i.e. source water is made potable (e.g. treated) at a centralized treatment plant and then delivered to users through a pressurized distribution system (Kyessi 2005). Though the most costly component of such systems is typically the excavation required to lay the pipes (USEPA 1991), centralized distribution systems are often considered the only way to provide water and sanitation services to densely populated urban areas where local water sources are often contaminated and unsuitable for consumption even after treatment. The requirement that cities served by such systems have sustained access to relatively high quality, reliable, extra-urban source water supplies, however, carries the potential to create upstream/downstream conflict, especially as urban growth infringes on source water watersheds.

While the planning, design, and construction of large centralized networks is often subsidized by the public or private sectors, recurring operation, maintenance, and repair costs are paid with revenues generated by user fees, often administered by a local governmental, quasigovernmental, or private body. The regular upkeep and repair of pressurized distribution systems requires specialized machinery and skilled labor, and may involve excavation, requiring that such infrastructure networks be accompanied by a trained team of water utility personnel.

Additionally, and because of the high cost associated with laying and maintaining pipes, centralized water distribution systems are typically designed to serve high density population centers only. The user costs associated with extension of the network into low density regions is typically much higher than the cost of providing exurban residents with a decentralized local water source (e.g. a protected well). As of 2010, only about $4 \%$ of the world's urban population relied on unimproved water supplies, compared to $19 \%$ of the rural population (UN 2012).

Though their benefits (e.g. improved public health, environmental protection, streamlined operations, economy of scale, reliability) are well known, centralized water and sanitation systems are not always feasible or appropriate. In developing world settings, for example, where financing or other capital funds may not be readily available, the startup costs to build a centralized water or sanitation system can be prohibitively high (Wilderer and Schreff 2000), and rural populations may lack a reliable source of energy for well pumps. In addition, if an economically stable user base is not present, the revenues needed to pay for recurring operation and maintenance costs cannot be guaranteed, a situation that can lead to gradually deteriorating system performance. Since damage to critical nodes or segments can compromise the functionality of the entire system, centralized infrastructure can also be vulnerable to environmental hazards such as earthquakes or hurricanes. In contrast to industrialized settings, where, on average and as a percentage of household income, the cost of a protected well or other decentralized water supply system is bearable for exurban residents, in developing world settings rural populations often rely on unimproved sources (UN 2012).

In such contexts, there has been growing interest by infrastructure experts, researchers, and international lending institutions in applying funds earmarked for improving water access in a decentralized manner (Wilderer and Schreff 2000). In a broad sense, decentralized 
infrastructure replaces centralized treatment and distribution systems with a network of smaller, individual facilities (e.g. point-of-use or on-site treatment, no centrally managed pipe systems). From a management standpoint, it replaces a team of mainly utility personnel with grass roots networks, which could include local water committees, and municipal (as opposed to regional or national) decision-making bodies. Decentralized water sources are accessed by users either through a large number of relatively small distribution systems, or directly at the pointof-use (Peter-Varbanets et al. 2009). When evaluated on per user basis, investments in decentralized water systems in rural areas are as cost-effective as in urban settings.

More generally, and compared to centralized systems, decentralized systems can have lower maintenance costs, can require fewer upgrades, and be installed incrementally in response to actual demand (Venhuizen 1991). Decentralized systems have independent components, making the system less vulnerable to systemic failures, hazards, and extreme environmental events (Venhuizen 1991). Additionally, expansion of a decentralized system can be easier because it is not contingent upon availability of treatment plant capacity, as is necessary in expansions to centralized systems (Mintz et al. 2001). A high level of service, however, is contingent upon the consistent availability of labor to operate and manage the entire decentralized network (Wolff and Gleick 2003).

\section{Geographic and infrastructure setting}

The commune of Leogane is distributed across a coastal plain and mountainous region located approximately $30 \mathrm{~km}$ to the west of Port-au-Prince. Approximately one-third of the commune's 300,000 people live in the city's urban center. The $\sim 114 \mathrm{~km}^{2}$ coastal plain is underlain by a productive shallow unconfined aquifer that typically can be accessed at depths of 5-10 meters below the surface. At greater depths (25-30 meters) a confining layer separates the unconfined aquifer from a deeper confined one. Two rivers bisect the commune and are accompanied by a multitude of smaller tributaries, irrigation canals, and drainage ditches.

The climate is marine tropical with a hot and humid summer and a cooler and drier winter season. There are two distinct rainy seasons; one April to June the other October to November. Leogane has no climate station but because it has similar topography, and is only $\sim 30 \mathrm{~km}$ west of Port-au-Prince, its weather can be characterized as similar to that of the capital (average annual rainfall $=1370 \mathrm{~mm}$, daytime temperature 25-30C). Haiti is hit, on average, by one cyclone (defined as a climatic event with windspeed over $250 \mathrm{~km} / \mathrm{h}$ ) with devastating effects every five years (Aquastat 2000).

Portions of the city of Leogane were, at one time, supplied with drinking water by a centralized gravity-driven distribution system built with international aid money in the early 1980s. The system was fed by an artesian spring on the eastern side of the Momance River. A main distribution line was buried in the river bed and resurfaced on the western side before continuing under the main road to Leogane's urban center, where it subdivided into a gridded distribution system covering about a $1 \mathrm{~km}$ by $1 \mathrm{~km}$ square region. Two smaller lines branched off the main line, one going to the north (the Matthieu branch) and one to the south (the Belle Fortune branch). Another small line branched off the downtown service area to serve $\mathrm{Ca}$ Ira in the northwest. In addition to this centralized distribution system, a smaller subsidiary system fed by another artesian spring supplied drinking water to an unknown service area. While these distribution pipes may have sustained additional damage due to the earthquake, the system had actually been rendered inoperable during the 2008 hurricane season when floods washed out the river bed and destroyed the piping buried in the bed. At the time of this study, responsibility for the defunct system was being transferred from the Service National d'Eau Potable, the national water utility located in Port-au-Prince, to a regional office of the Direction Nationale de l'Eau Potable et de l'Assainissement, as part of the decentralization and reorganization of the water sector in progress throughout Haiti under the terms of a 2009 national water law.

The goal of this study was to elicit local perspectives on how reconstruction funds could be used to improve post-earthquake access to water services in Leogane. By documenting local preferences, the intention was to assist the reconstruction effort, namely by helping foreign donor agencies with the financial wherewithal to make key infrastructure investments in Leogane better understand local needs. Assessing whether local opinion favors a decentralized or centralized strategy for meeting the city's water needs from afar is difficult. Though evidently Leoganais have coped with informal decentralized infrastructure for some time, at the time of this study postearthquake reconstruction was viewed by many in Haiti as an opportunity to "build back better" (Fountain, 2010). Accurate or not, a higher quality of life is associated by some with centralized systems. To the extent that they are more reliant on local management structures, decentralized strategies could be viewed favorably by individuals with a low level of confidence in the government's ability to effectively solve development problems.

\section{Methods}

The overall methodology involved a number of different research activities intended to survey rapidly the perspectives of a wide range of stakeholders. The full research team included four professors (three engineers and one social scientist), three community planners from Leogane, six trained Haitian enumerators, and five 
trained Haitian workshop facilitators. All field work was performed over a five month period, including two, oneweek trips by the research team to Leogane (May-June and July-August of 2010). All activities involving human subjects were reviewed and approved by Drexel University's Institutional Review Board for the Protection of Human Subjects. A paper survey implemented on the streets of Leogane using the Kreyòl-speaking enumerators $(\mathrm{n}=171)$ was completed, and a series of interviews (semi-structured, $\mathrm{n}=19$, and in-depth open-ended, $\mathrm{n}=6$ ) as well as more general participant observations made at two different Water, Sanitation and Hygiene (WASH) cluster meetings were held. The field research culminated with a full-day participatory workshop attended by 76 local community members during the second trip. Details on only those aspects of the full methodology that are relevant to the research presented in this paper are further elaborated below.

\section{Structured Paper Survey of Infrastructure Practices and Preferences}

During the first trip, the researchers trained six Haitian university students who administered a paper survey in Kreyollthroughout the Leogane region. The survey consisted of 42 questions about pre- and post-earthquake water and sanitation conditions, practices, and problems. A convenience sample of 171 respondents was obtained

\section{Table 1 Demographics of survey participants}

\begin{tabular}{lll}
\hline & $\begin{array}{l}\text { Number of } \\
\text { respondents }\end{array}$ & $\begin{array}{l}\text { Percentage of } \\
\text { respondents }\end{array}$ \\
\hline Age group & 3 & \\
18 years and under & 54 & $1.7 \%$ \\
$19-30$ years & 54 & $29.8 \%$ \\
$31-50$ years & 46 & $29.8 \%$ \\
51 years and over & 24 & $25.4 \%$ \\
Didn't answer & & $13.3 \%$ \\
Gender & 90 & \\
Male & 81 & $49.7 \%$ \\
Female & 10 & $44.8 \%$ \\
Didn't answer & & $5.5 \%$ \\
Employment & 53 & \\
Employed & 118 & $29.3 \%$ \\
Unemployed & 10 & $65.2 \%$ \\
Didn't answer & & $5.5 \%$ \\
Location & 58 & $32.0 \%$ \\
City center & 17 & $9.4 \%$ \\
City periphery & 95 & $52.5 \%$ \\
Outlying areas & 10 & $5.5 \%$ \\
Didn't answer & & \\
\hline
\end{tabular}

from the city, urban peripheral and outlying areas of Leogane. Table 1 lists the age, gender, employment status, and location of the participant's home before the earthquake for all survey respondents. Approximately $60 \%$ of participants were between the ages of 19 and 50 , and approximately $25 \%$ were over 50 years old. Males and females were about equally represented $(49.7 \%$ and $44.8 \%$, respectively). While $65.2 \%$ of participants considered themselves to be "unemployed," some were selfemployed and/or worked in agriculture. A majority of participants (52.5\%) were from outlying areas of the city. About one third (31.6\%) of the respondents were living at the same location and in the same house as before the earthquake; $22.8 \%$ were living at the same location but in a new or reconstructed house; $25.1 \%$ were living in temporary camps. The remainder was living with friends, relatives, or in another location.

The survey included the "core questions" used by WHO and UNESCO (2005) for quantifying the percentage of a population that has reasonable access to water and sanitation. The responses were analyzed to determine the number and percentage of participants who used different water systems prior to the earthquake, and also to characterize reconstruction preferences. Because all respondents did not respond to all questions, there were slight differences in the number of responses to individual questions. We used the survey results to explore whether different water sources were used for different water needs (e.g. cooking, agriculture, hygiene, and religious or ceremonial use). Contingency tables were developed using Microsoft Excel and SPSS 19 (IBM Corporation, Armonk, NY), breaking down the results based on age, gender, geographic origin, and employment status. For categorical variables, Pearson's chi-square test was used to assess if response frequencies differed significantly by any of these factors. For continuous variables, t-tests were used to assess differences in means.

Several assumptions needed to be made to classify specific survey responses as referring to either "centralized" or "decentralized" systems (Table 2). For reference, "decentralized" water systems are assumed to include wells, surface water sources, harvested rainwater, springs, water bladders, tanker-trucks, the use of a cart and tank or drum, and bottled water. For the purposes of this paper, "centralized" water systems are assumed to include piped water (into the dwelling or yard/ plot) and public taps or standpipes. In general, public standpipes may be fed by wells or by a piped supply. In Leogane, all functioning taps were fed by wells since the public water supply was not functioning at the time of the study. While public taps are physically "decentralized" when fed by local wells, they nevertheless require institutional arrangements to apportion costs among users and for this reason are classified as "centralized" in this study. 


\begin{tabular}{|c|c|c|}
\hline \multirow[t]{13}{*}{ Water source } & \multirow[t]{3}{*}{ Centralized } & Piped (Into Dwelling) \\
\hline & & Piped (Into Yard) \\
\hline & & Public tap/standpipe \\
\hline & \multirow[t]{10}{*}{ Decentralized } & Well (Artesian) \\
\hline & & Well (Using Bucket) \\
\hline & & Well (Using Pump) \\
\hline & & Surface water \\
\hline & & Rainwater collection \\
\hline & & Unprotected spring \\
\hline & & Protected spring \\
\hline & & Cart with small tank/drum \\
\hline & & Tanker-truck/water bladder \\
\hline & & Bottled water \\
\hline
\end{tabular}

\section{Semi-structured Interviews}

Interviews were carried out during both trips, and also by telephone from the United States. The 19 semistructured interviews were conducted by convenience sample, and consisted of current residents of Leogane, expatriate former residents of Leogane, and nongovernmental organization (NGO) representatives. These interviews were conducted by one or two team members (with a Kreyòl translator when required,) and digitally recorded. Based on a standardized set of "discussion points" and follow up questions, each interview lasted approximately 45 minutes. The recorded interviews were transcribed in English and coded for analysis with ATLAS.ti (Berlin, Germany). Analysis identified broad patterns of types of responses, common themes, actors mentioned, linkages between problems identified and solutions suggested, and enabled comparison of different groups of interviewees. A separate protocol was also used to check for the presence or absence of certain basic ideas and concepts. This protocol used contingency tables to identify trends similar to those in the structured surveys: by age, gender, geographic origin, and employment status.

\section{Workshop}

During the second trip in July/August 2010, the research team conducted a full-day participatory workshop. The team trained 10 Haitian facilitators, and the workshop involved 76 community stakeholders who were identified during the first trip. These local stakeholders and community leaders represented a range of organizations, such as youth associations, women's organizations, professional organizations, and small farmer's organizations. During the workshop, participants were asked to propose, discuss, prioritize, and elaborate solutions to Leogane's water and sanitation problems. First, five groups of ten to fifteen brainstormed solutions. By vote, these groups brought their five top ranking ideas to the general assembly of all workshop participants. The general assembly voted on the 25 solutions proposed by the five groups, and the five top ranking solutions were elaborated more thoroughly during afternoon breakout sessions into proposals. Pre- and post-workshop surveys with Likert Scale questions were used to gage participant satisfaction with the process and results. Overall, 95\% of the respondents characterized the workshop as "a success", with $\sim 79 \%$ strongly agreeing and $\sim 19 \%$ agreeing with its conclusions. ATLAS.ti was used to quantify the frequency with which different kinds of centralized and decentralized water and sanitation options were mentioned in all of the proposed ideas. The final five proposals emerging from the workshop are also scrutinized to infer preferences regarding the preferred degree of centralization of post-earthquake infrastructure.

\section{Data Deposition}

The paper surveys, as well as the pre- and post- workshop survey results were transported back to Drexel University where the results were entered into digital data files for analysis in Excel and SPSS. With the assistance of native Kreyòl speakers, the interviews were recorded, translated, and transcribed for analysis with ATLAS.ti.

\section{Results}

The results section presents relevant findings from the paper survey and workshop, and the contingency analyses. The results of the semi-structured interviews are integrated into the Discussion.

\section{Synthesis of paper survey results}

Figure 1 depicts the percentage of respondents who indicated that they accessed different sources of water at different levels of frequency. The three most common water sources accessed for daily needs were well using bucket (35\%), public tap/standpipe (28\%), and well using pump (12\%).

Figure 2 is a bar chart depicting the different sources of water accessed by the participants for different uses prior to the earthquake. The bars break down the responses for each use by source. Overall, the top two sources for cooking, clothes washing, hygienic needs, and drinking were "well using bucket", and "public tap/standpipe". Prior to the earthquake, approximately $40 \%$ of all respondents relied on "public tap/standpipes" for cooking, clothes washing, hygienic purposes, and drinking. For this same set of uses, the second most frequent source was "well using bucket", but it is noteworthy that the percentage of respondents who relied on "well using bucket" for drinking purposes $(<20 \%)$, was significantly lower than for the other uses (30-40\%). Stated differently, groundwater accessed using wells and 


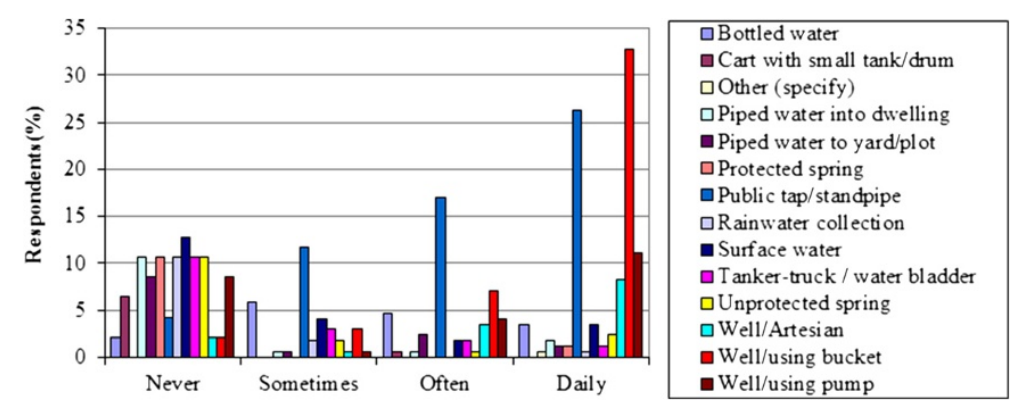

Figure 1 Frequency of water source use.

buckets was used for nonpotable purposes more frequently than for drinking. Water that was intended for ingestion was more frequently accessed from the "public tap/standpipe" (which may actually have originated in a local borehole).

Of 170 respondents, $74.1 \%$ said they treated water before drinking it (Figure 3), and the most common form of household treatment was a locally available bleach tablet, known as Aquatab (Figure 4). Perhaps because they treated water before drinking, very few respondents listed "sickness" or "death" as among the problem with their pre-earthquake water source. More commonly cited problems were "a long queue," "water is not always available" or "tastes bad or looks dirty" (Figure 5). Figure 6 displays the average number of minutes required to access different water sources, (includes travel to and from the source, waiting and extraction time, but excludes all socializing time). On average, springs require about an hour, while public taps, artesian wells and wells with pumps require about half that time. Based on travel time, wells accessed using buckets appear to have been most readily accessed at 11 minutes. Women were more likely than men or children to be responsible for fetching water from all sources except artesian wells (Figure 7). We speculate that because they are very expensive to install, artesian wells may be culturally associated with male-dominated economic activities in Haiti and are therefore less accessible to women (see Sheller et al. 2013 for a wider discussion of gender, water access, and sanitation issues relating to this study). In Figure 8 the various reported sources are classified as either centralized or decentralized. With the exception of water used for sanitary purposes and water used for commercial food production, decentralized sources were more frequently used than centralized ones. Table 3 is a comparison of pre-earthquake drinking water sources used with the source type that the respondents would prefer to use after the rebuilding process. More than half (53\%) of those surveyed stated that they used a decentralized water source to obtain drinking water prior to the January earthquake. However, when asked, "As Leogane is rebuilt after the earthquake, which source of water would you prefer to be available to you?" $83 \%$ said they would prefer a centralized one. More detail is provided in Figure 9, which shows that for cooking, clothes

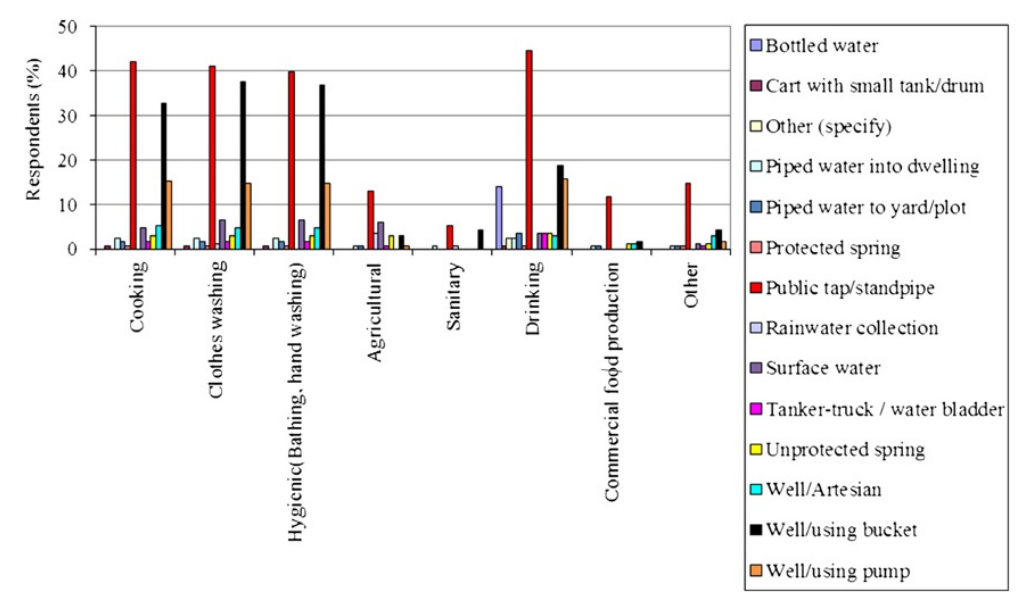

Figure 2 Water sources used prior to the earthquake. 


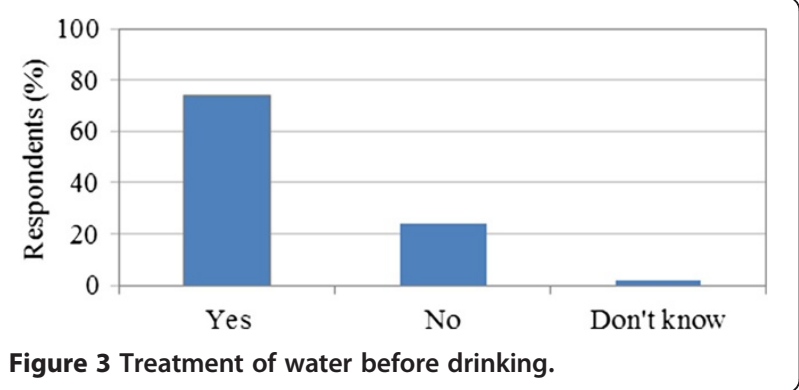

washing, hygienic purposes and drinking, survey respondents expressed a preference for "piped water to yard/plot" and "piped water into dwelling" above all other sources.

\section{Synthesis of Workshop Results}

The workshop was structured to allow the participants to discuss a wide range of water and sanitation issues for Leogane. Figure 10 displays the number of times different phrases were mentioned during the workshop, as computed using ATLAS.ti. Of those phrases pertaining to water sources, "artesian wells" (a decentralized water source) were mentioned the most frequently (15 times), followed by "extending the piped water system" (13 times), and "capped" or "captured" sources (12 times). Sometimes these suggestions co-occurred, i.e. with "digging of artesian wells" mentioned in the same sentence as "extending the piped water system" (5 times) so that overall the preference seemed to be for a mixed system, including both centralized and decentralized strategies.

As measured by the number of votes, the "top five" proposals identified by the participants are listed below. These were then elaborated further during the afternoon sessions.

1. Protect the environment in the city and in the plains, from the mountaintops down to the valleys.
2. Promote hygiene, repair and extend the piped water system to more homes, build artesian wells, public fountains with potable water, and modern bathrooms in every home.

3. It is important that each neighborhood has its own water system, build public and private bathrooms, and make sure people pay for the services.

4. Protect the water sources, treat water and dig canals for irrigation purposes.

5. Dig more artesian wells, lay more pipes, and we need a surveillance committee and to plant more trees.

These proposals contain a variety of references to both centralized and decentralized water systems. The second proposal makes a clear reference to both centralized (e.g. "piped water system"), and decentralized (e.g. "artesian wells") drinking water systems. Water in "public fountains" could be sourced either from an artesian aquifer or reservoir connected to it with pipes. The joint references to "public fountains", "artesian wells" and "piped water" is more indicative of a goal of improving access to water services in general, than to a preference for a particular modality of infrastructure. The third proposal also suggests a desire for consistent levels of service "in each neighborhood". Although there are different ways that water services could be provided to a neighborhood, no preference for how centralized the approach should be was articulated. The fifth proposal also cites both centralized (e.g. "pipes") and decentralized (e.g. "artesian wells") solutions.

A number of phrases and terms in these proposals suggest that generally the participants view decisions related to water as also related to a variety of other local issues. For example, the first proposal suggests that the participants see a relationship between water issues and protection of the larger Leogane environment. The fourth proposal recognizes both the need for treatment

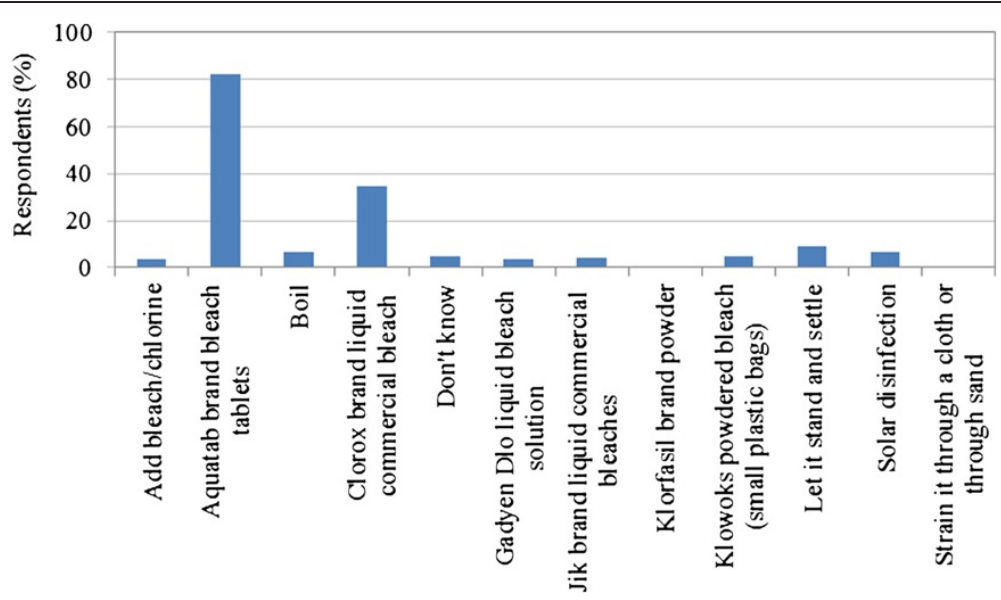

Figure 4 Type of water treatment. 


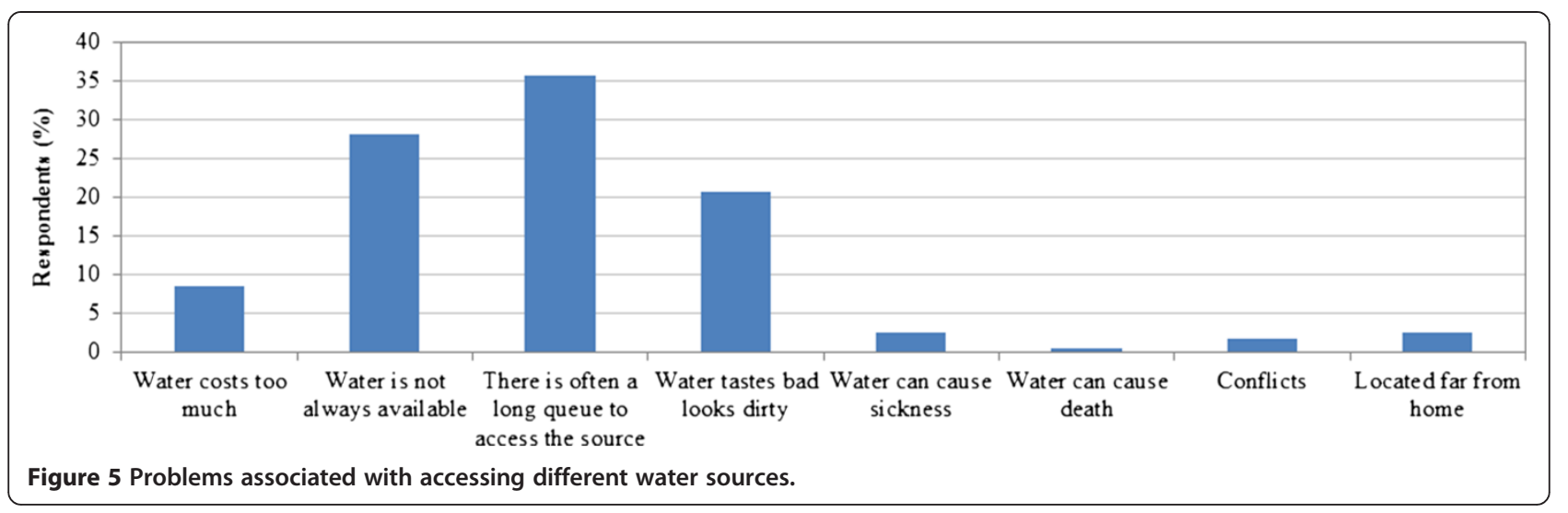

(consistent to the survey results) and mentions agricultural water needs, a topic not specifically emphasized in the workshop preamble (and generally invisible in the larger post-earthquake planning processes taking place nationally and internationally). The fifth proposal suggests that deforestation (usually attributed to charcoal making) is viewed as having an important role in local water issues.

Participants gave relatively high priorities to both centralized and decentralized strategies (Table 4) on both the pre- and post-survey. For example, on a scale of 1 through 5, workshop participants ranked all options, both centralized and decentralized, relatively highly (>4.3). The pre- and post workshop responses were not significantly different, except for "extend piped water supply" which increased from 4.35 to 4.97 (p-value of 0.001 for an independent samples t-test). While this one centralized option did receive higher ratings, ratings for the de-centralized options did not decline.

\section{Results of Contingency Analysis}

The survey results indicate that while most participants seem to have relied on decentralized water sources prior to the earthquake, the majority would prefer reconstruction funds to be used to construct a centralized water system. However, the interviews and workshop results also suggest that the study participants see a blend of centralized and decentralized strategies as essential in the broader quest to improve the post-earthquake water situation. We investigated whether relationships exist between the employment status, gender, age group, or household location of the participants and a) the degree to which they were reliant on decentralized sources and, b) the likelihood with which they expressed a preference for centralized water sources.

\section{Contingency analysis on survey participants who relied on decentralized sources before the earthquake}

The survey results indicate that before the earthquake the majority of all survey participants obtained drinking water from decentralized sources. In Table 5, these results are broken down by age group, employment status, gender, and location, and the significance of the differences in responses tested using a Pearson's chi-square test. Reliance on decentralized sources varied significantly ( $\mathrm{p}=0.027)$ only by employment status. Of those

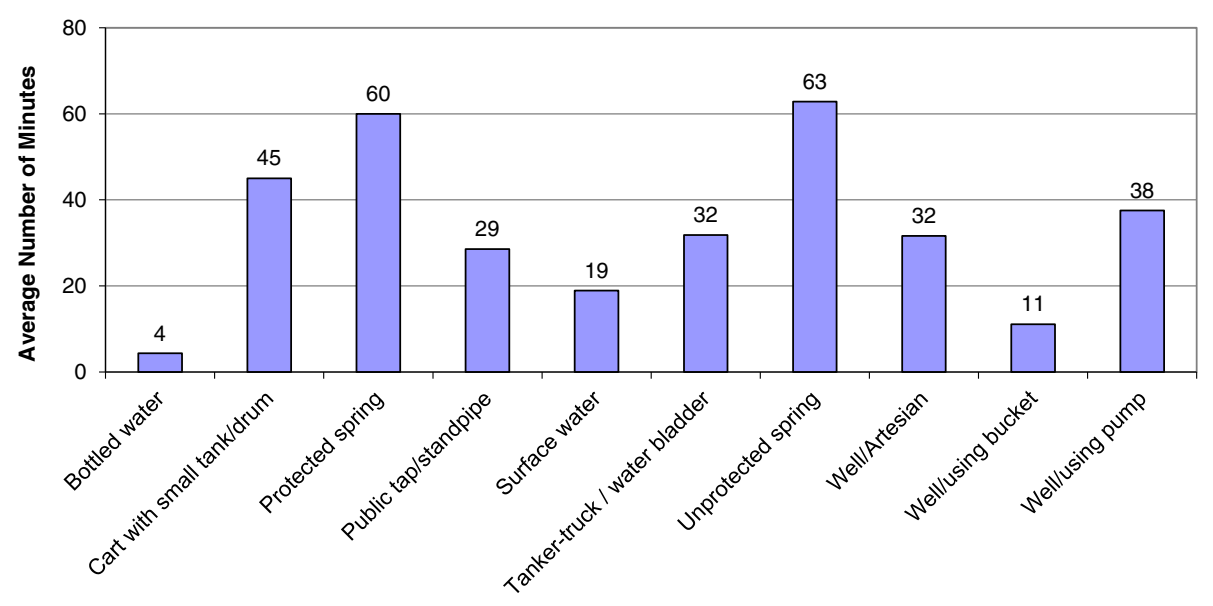

Figure 6 Time needed to access different water sources $(n=168)$. 


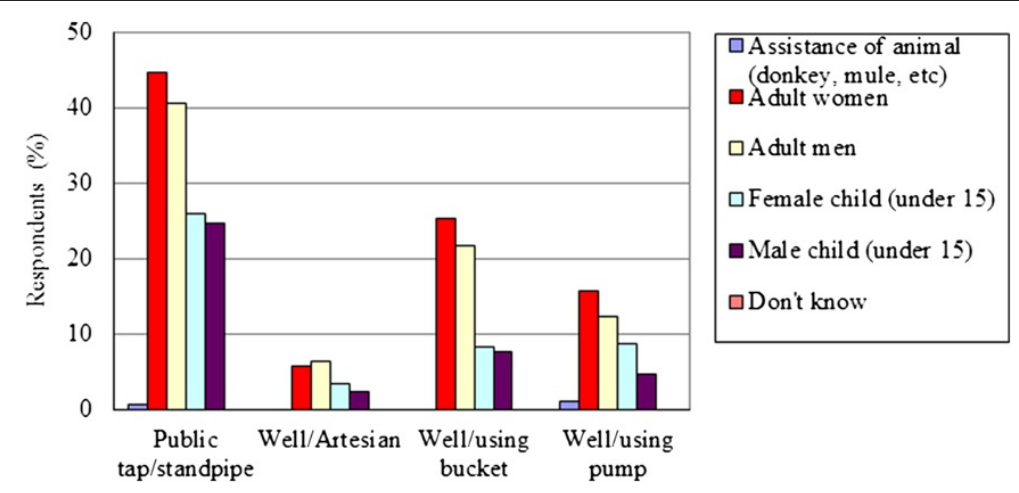

Figure 7 Household member responsible for collecting water.

unemployed, 58.4\% relied on a decentralized water system, compared to only $41.2 \%$ of employed participants. A small difference was also observed between geographic areas. The city periphery relied less heavily (e.g. $35.3 \%$ of respondents) on decentralized water sources than did the city core (53.8\%) or outlying areas (55.8\%), though these results were not statistically significant $(\mathrm{p}=0.356)$. Assuming that centralized water sources are generally more costly to build, operate, and maintain than decentralized ones, the contingency analyses suggest that participants from two specific groups, (e.g. residents of rural areas and younger survey participants), had less access to capital intensive technologies than the rest of the sample.

\section{Contingency analysis on survey participants who prefer centralized sources}

Overall, the paper survey suggests a general preference for centralized, and specifically piped, water systems. Over $80 \%$ of participants in all age groups preferred a centralized water source; as did 100\% of participants from the city periphery, and more than $80 \%$ of those from the city core and outlying areas. Contingency analyses were used to test for significant differences among the responses of participants from different groups. Differences between individuals of different age groups, employment status, gender and location were found to be insignificant.

The interview responses were also analyzed to determine if specific groups of interviewees expressed a greater preference for centralized sources. When discussing potential solutions to the city's current water problems, 13 participants mentioned piped water, and no participants were opposed to it. Interviewees mentioned repairing the piped water system 4 times; mentioned building reservoirs and river channeling 4 times; and bringing water to each home twice. These specific suggestions, along with 8 statements that the Government should be responsible for water provision, all suggest a preference for centralized systems.

Water sources classified as centralized or decentralized

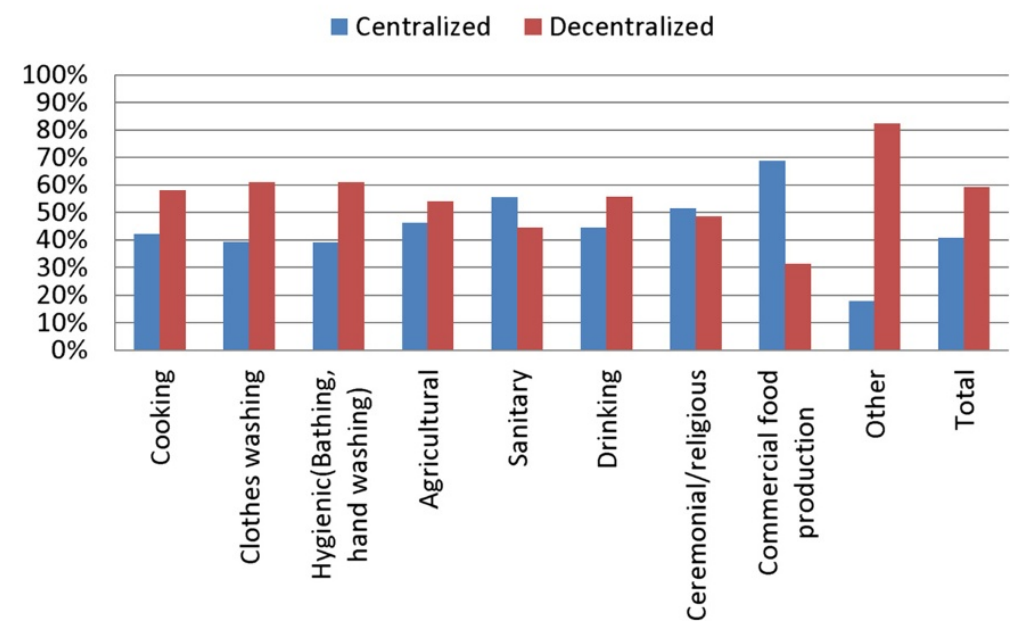

Figure 8 Water sources classified as centralized or decentralized. 
Table 3 Comparison of pre-earthquake water sources usage with reconstruction preferences

\begin{tabular}{lllll}
\hline Water source & \# Using before earthquake & \% Using before earthquake & $\begin{array}{l}\text { \# Who would prefer } \\
\text { this source/system }\end{array}$ & $\begin{array}{l}\text { \% Who would prefer } \\
\text { this source/system }\end{array}$ \\
\hline Centralized & 59 & $36.0 \%$ & 137 & $83.0 \%$ \\
Decentralized & 87 & $53.0 \%$ & 28 & $17.0 \%$ \\
Combination & 18 & $11 \%$ & 0 & $0.0 \%$ \\
\hline
\end{tabular}

$\mathrm{N}=161$ responses for pre-earthquake water source; $\mathrm{N}=165$ for reconstruction preference.

\section{Discussion}

The interview and workshop results were analyzed to test whether the widely expressed preference for centralized sources was accompanied by a negative view of decentralized water sources. The analysis revealed mixed views of decentralized sources. For example, five interviewees actually viewed wells as a solution versus only three who did not. One interviewee favored wells "because at the pipe (e.g. standpipe) you have to stand and wait... you can dig the artesian well... and have a common well... at a central place." Six out of seven local interviewed residents of Leogane expressed that it would be acceptable to share a water source among a couple of families (or a shared courtyard, known locally as lakou), as did two of the Haitian professionals who lived abroad and one of two nongovernmental organization representatives.

It is plausible that the mixed opinions of decentralized sources derive from different perspectives regarding the safety of consuming groundwater, and the potential effectiveness of home water treatment techniques. The paper survey results indicated that groundwater accessed from wells using buckets was more frequently used for nonpotable purposes than for drinking. In $90 \%$ of the interviews, participants explicitly stated that the local groundwater is not safe to drink, and only one participant believed that shallow groundwater was safe to consume. An excerpt from an interview with a Leogane resident stated that well water "was mainly used for washing clothes or baths, cleaning and stuff like that. The only thing is we don't drink it." Another stated that "people do their best to use clean water for cooking. Not so much the well. I don't recall people using the well that much unless there was not water whatsoever". Another interviewee "thinks his well is as good as the guy's next door, but for drinking purposes he prefers the [water] from the tap."

The paper survey indicated that $74.1 \%$ of respondents treated water before drinking it, and the interviews substantiate this finding but also reveal some skepticism about the effectiveness with which home treatment is administered. Of 19 interviewees, 14 were familiar with home water treatment methods, four did not mention the subject in their interview, and only one interviewee (a resident of Leogane) was not familiar with home water treatment. Fourteen interviewees stated that they treat their water before drinking, though one individual also relayed that some people "drink from the well without treating it." Three interviewees viewed home water treatment as a solution to the water problem, and only

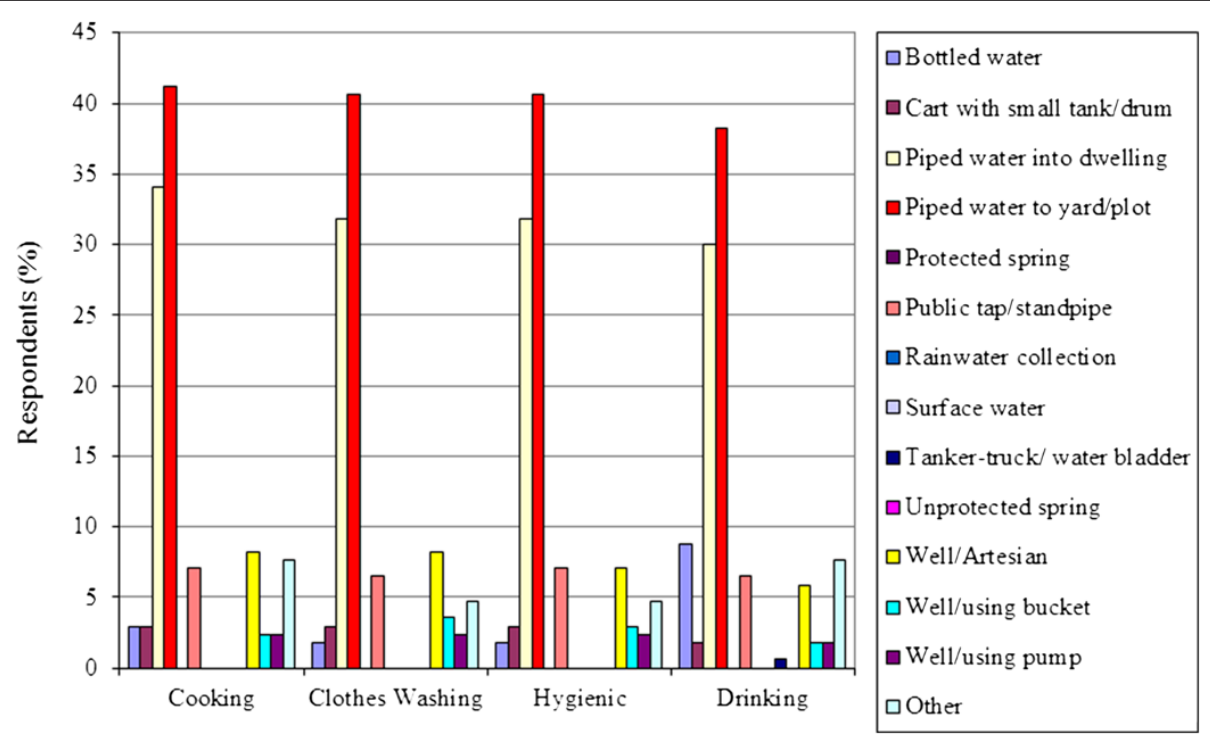

Figure 9 Reported preferences for water sources. 


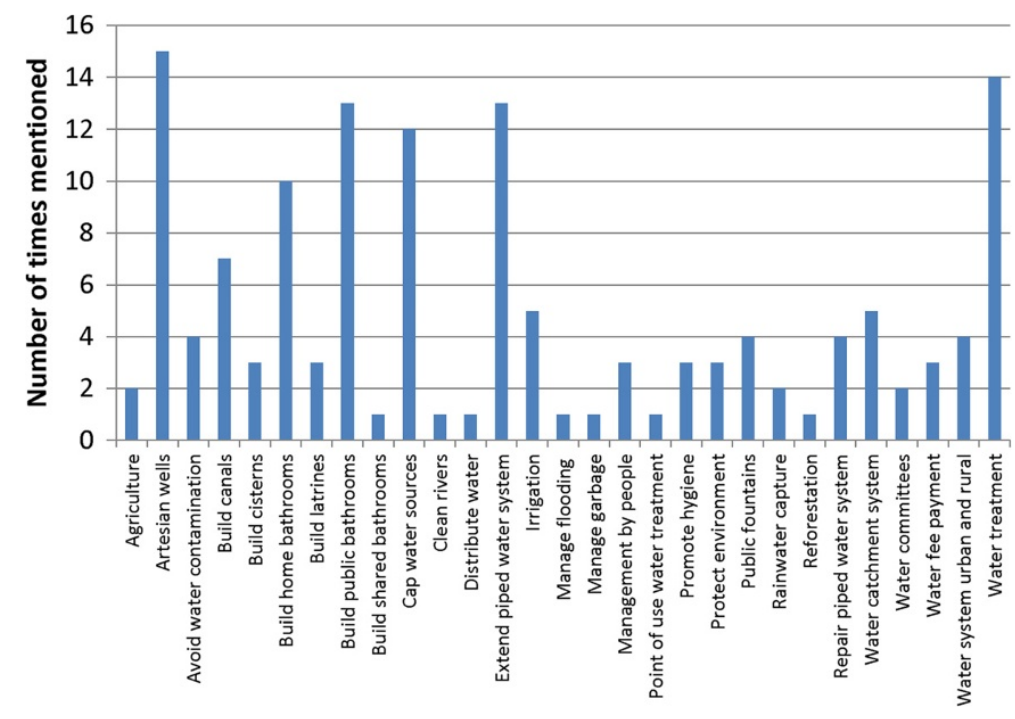

Figure 10 Workshop ideas for Leogane water and sanitation initiatives (counted based on ATLAS.ti coding of written notes from 5 morning sessions).

one person did not think it was an appropriate solution. However, even those with a favorable view of home treatment may still be interested in a centralized water supply. One local explained his preferred solution: "divert the water into people's homes. The water would be treated but even if it wasn't you could treat it at home." In the post-workshop survey, >90\% of participants indicated that it is important (Likert score 4.87, see Table 4) that training and support be provided for people to treat water at home so it is safe to drink.

Together, these results suggest that while local residents are generally used to treating water in the home, and are potentially willing to continue doing so, there is some uncertainty regarding how effective they believe local residents would be in administering it without additional training. Providing such training did not emerge from the workshop as a high priority. These local attitudes align with the concern expressed by a metaanalysis (Hunter 2009) that disinfection-only techniques (i.e., the approaches most widely used in Leogane) offer little long term benefit.

Although gender differences were found to be insignificant in terms of preferences for centralized versus decentralized water infrastructure, we have explored gender issues in water and sanitation access further in Sheller et al. (2003: 26), where we conclude that after the earthquake: "Disruptions to the water supply system posed particular burdens for women, including waiting in long queues to get water, being unable to access clean drinking water, and having to deal with the cost and responsibility of home treatment of water. Weak sanitation infrastructure increased risks of exposure to cholera, failed to address the hygiene needs of women and children, potentially left women vulnerable to physical insecurity, and burdened women with unpaid cleaning duties."

\section{Conclusion}

As of this writing, (more than three years after the earthquake), very little of the reconstruction funds pledged in the immediate aftermath of the earthquake have materialized. Delays in disbursement have been associated with disputes over land titles, a governmental administrative structure that was weakened and decimated by the earthquake itself, and a drawn out national election process. By December 2011, according to the World Bank (Country Brief 2012), the international community

Table 4 Mean results of pre and post workshop surveys

\begin{tabular}{|c|c|c|}
\hline \multirow[t]{2}{*}{ Question } & \multicolumn{2}{|l|}{ Mean } \\
\hline & Pre-workshop & Post-workshop \\
\hline \multicolumn{3}{|l|}{ Centralized Water Source } \\
\hline \multirow{2}{*}{$\begin{array}{l}\text { Repairing the EXISTING piped } \\
\text { drinking water distribution } \\
\text { system }(p=0.175)\end{array}$} & $N=60$ & $N=30$ \\
\hline & 4.8 & 4.94 \\
\hline \multirow{2}{*}{$\begin{array}{l}\text { Extending the EXISTING piped } \\
\text { drinking water distribution } \\
\text { system }(p=0.001)\end{array}$} & $N=55$ & $N=31$ \\
\hline & 4.35 & 4.97 \\
\hline \multicolumn{3}{|l|}{ Decentralized Water Source } \\
\hline \multirow{2}{*}{$\begin{array}{l}\text { Constructing more borehole } \\
\text { (lined and protected) wells that } \\
\text { tap a deep, high quality source } \\
\text { of water }(p=0.665)\end{array}$} & $N=57$ & $N=31$ \\
\hline & 4.47 & 4.35 \\
\hline \multirow{2}{*}{$\begin{array}{l}\text { Training and support for people } \\
\text { to treat their water at home so } \\
\text { it is safe to drink ( } p=0.955)\end{array}$} & $N=59$ & $N=31$ \\
\hline & 4.86 & 4.87 \\
\hline
\end{tabular}


Table 5 Number and Percentage of participants using different water sources before the earthquake and preferences for rebuilding, divided by age group, employment, gender, and location

\begin{tabular}{|c|c|c|c|c|c|c|}
\hline & \multicolumn{2}{|l|}{ Centralized } & \multicolumn{2}{|l|}{ Decentralized } & \multicolumn{2}{|l|}{ Combination } \\
\hline & $\begin{array}{l}\text { Pre-earthquake } \\
(\mathrm{n}=59)\end{array}$ & $\begin{array}{l}\text { Preference } \\
(n=137)\end{array}$ & $\begin{array}{l}\text { Pre-earthquake } \\
(\mathrm{n}=87)\end{array}$ & $\begin{array}{l}\text { Preference } \\
(n=28)\end{array}$ & $\begin{array}{l}\text { Pre-earthquake } \\
(n=18)\end{array}$ & $\begin{array}{l}\text { Preference } \\
(\mathrm{n}=0)\end{array}$ \\
\hline \multicolumn{7}{|l|}{ Age Group } \\
\hline 0 to 30 years $(n=57)$ & $42.1 \%$ & $83.6 \%$ & $45.6 \%$ & $16.4 \%$ & $12.3 \%$ & 0 \\
\hline 31 to 50 years $(n=54)$ & $35.8 \%$ & $82.0 \%$ & $50.9 \%$ & $18.0 \%$ & $13.2 \%$ & 0 \\
\hline 51 years and over $(n=46)$ & $33.3 \%$ & $87.0 \%$ & $57.8 \%$ & $13.0 \%$ & $8.9 \%$ & 0 \\
\hline \multicolumn{7}{|l|}{ Employment } \\
\hline Employed ( $n=53)$ & $39.2 \%$ & $80.4 \%$ & $41.2 \%$ & $19.6 \%$ & $19.6 \%$ & 0 \\
\hline Unemployed $(n=118)$ & $34.5 \%$ & $84.2 \%$ & $58.4 \%$ & $15.8 \%$ & $7.1 \%$ & 0 \\
\hline \multicolumn{7}{|l|}{ Gender } \\
\hline Male $(n=90)$ & $37.6 \%$ & $81.4 \%$ & $54.1 \%$ & $18.6 \%$ & $8.2 \%$ & 0 \\
\hline Female $(n=81)$ & $34.2 \%$ & $84.8 \%$ & $51.9 \%$ & $15.2 \%$ & $13.9 \%$ & 0 \\
\hline \multicolumn{7}{|l|}{ Location } \\
\hline City Core $(n=58)$ & $34.6 \%$ & $80.4 \%$ & $53.8 \%$ & $19.6 \%$ & $11.5 \%$ & 0 \\
\hline City Periphery $(n=17)$ & $58.8 \%$ & $100.0 \%$ & $35.3 \%$ & $0.0 \%$ & $5.9 \%$ & 0 \\
\hline Outlying Areas $(n=95)$ & $32.6 \%$ & $81.7 \%$ & $55.8 \%$ & $19.3 \%$ & $11.6 \%$ & 0 \\
\hline
\end{tabular}

had delivered over half of the pledges intended in the first 24 months (US $\$ 5.5$ billion): but US $\$ 1$ billion went immediately toward debt relief and only US $\$ 2.4$ billion was spent (out of US $\$ 4.5$ billion approved) on projects and programs; a large percentage of which returned to the country of origin of the organizations carrying out the projects. A year later, according to the New York Times (Sontag 2012) “...just a sliver of the total disbursement - \$215 million - has been allocated to the most obvious need: safe permanent housing... While at least $\$ 7.5$ billion in official aid and private contributions have indeed been disbursed....disbursement does not necessarily mean spent." Significant amounts were still unallocated; “...the United States has more than $\$ 1$ billion allocated for Haiti sitting in the treasury, and the global Red Cross movement has more than $\$ 500$ million in its coffers". Yet close to half a million people remained without adequate shelter, potable water, and sanitation three years after the disaster (Schuller and Morales 2013). Overseas development aid ultimately totaled only $\$ 3.65$ billion in 2010 and $\$ 2.57$ billion in 2011, according to the OECD (2013).

While the ongoing delays in assistance are distressing, the overarching goal of this research was not to track how much of the pledged money arrived and how it was spent, but rather to inform eventual decision-making processes regarding water infrastructure by surveying local preferences. This goal was accomplished by piloting a unique participatory process in Leogane - one that could be replicated elsewhere. If money were made available for building a water system, how could stakeholder needs be considered in decisions regarding its disbursement? Could such decisions be made rapidly and could they generally promote social, ecological, and economic sustainability, as articulated by the local population? In what ways could decision makers involve local stakeholders in such decisions?

The results paint a picture of clear water infrastructure preferences against a backdrop of highly inadequate preearthquake water access conditions. Though most of the study participants relied on decentralized sources prior to the earthquake, more than four fifths of the survey respondents expressed a preference for a centralized water system going forward. Study participants specifically cited a piped water system for cooking, clothes washing, hygienic purposes and drinking. However, and despite the clear preference among survey participants for piped water systems, the interviews and the workshop suggest that local stakeholders see this piped water system as part of a broader, integrated solution to the region's water problems.

This integrated vision is in contrast to the current government plan that would make initial investments only in repairing the piped water system. The mixed-system of both centralized and decentralized water infrastructure strategies seems to reflect local stakeholders' nuanced understanding of the complexity of the local water problem. A hybrid plan could potentially offer more resilience in the face of disasters, than one reliant on centralized infrastructure alone. Indeed, Leogane's piped water system had failed before as a result of a hurricane, and this fact may be ingrained in the collective 
understanding of what does and does not work in this particular environment. A hybrid approach could also ensure a higher degree of access to clean water, especially for those not in the more densely populated city center, or who are unable to afford regular monthly payments.

These results are, of course, limited by our use of convenience sampling techniques that may not have been representative of the entire population. Unfortunately, no official population census data was available to which we could compare our sample. Nonetheless, this study gives insight into the types of water systems that Leoganais originally used and could have a preference for during the rebuilding process. Moreover, the study demonstrates a participatory process that infrastructure planners could use first to elicit and document local knowledge and preferences, and then use as a template for planning infrastructure systems. This kind of a process, if undertaken systematically, could help to generate community participation in government or donor financed development efforts, leading to greater legitimacy and sustainability in the long run. As a local Haitian stated, "The important thing is to work together and continue to work towards a common goal."

\section{Competing interests}

The authors declare that they have no competing interests.

\section{Authors' contributions}

$H G, T B$, and SO performed data analysis with oversight by PG. MS performed the Atlas TI analysis. FM completed the first draft of the manuscript. All authors revised the initial draft and approved of the final draft.

\section{Acknowledgements}

This project was sponsored by National Science Foundation through its RAPID solicitation via the Sustainability program in the ENG Directorate (grant ENG 1032184). Campbell's Soup Co. generously donated a laptop computer for the collection of data in the field. Contech also made a financial contribution to the project. ATLAS.ti made their software available. The authors would like to thank Jean Vernet, Lavaud Vernet, Yves Rebecca, Zach Nord, and Adam Zahn for their contributions to this project.

Responsible editor: Michael Piasecki

\section{Author details}

${ }^{1}$ Department of Civil, Architectural and Environmental Engineering, Drexel University, 3141 Chestnut Street, 19104 Philadelphia, PA, USA. ${ }^{2}$ Center for Mobilities Research and Policy Department of Culture and Communication Drexel University, 3141 Chestnut Street, 19104 Philadelphia, PA, USA. ${ }^{3}$ Engineering Cities Initiative, Drexel University, 3141 Chestnut Street, 19104 Philadelphia, PA, USA.

Received: 24 April 2013 Accepted: 18 October 2013 Published: 12 February 2014

\section{References}

Aquastat (2000) Haiti Fact Sheet, accessed online on October 4, 2013 at http:// www.fao.org/nr/water/aquastat/data/cf/readPdf.html?f=CF_HTI_en.pdf

BBC (2010) UN pledges $\$ 10$ billion to rebuild Haiti. Accessed online at: http:// news.bbc.co.uk/2/hi/americas/8598153.stm

Country Brief (2012) "Haiti - Population." Haiti - Population. US Library of Congress Country Studies, 2010. Web. 15 Mar. 2013. http://countrystudies.us/hait/21.htm
Fountain H (2010) Managing disasters with small steps. The New York Times. January 26, 2010, pp D1; http://www.nytimes.com/2010/01/26/science/ 26fault.html?pagewanted=all\&_r=1\&

Galada HC, Gurian PL, Montalto FA, Sheller M, Piasecki M, Ayalew T, O'Connor S (2013) Attitudes toward Post-Earthquake Water and Sanitation Management and Payment Options in Leogane, Haiti. Water International 38(6):744-757

Greenwood D, Levin M (1998) Introduction to action research: Social research for social Change. Sage Publications, Thousand Oaks, CA

Hunter PR (2009) Household water treatment in developing countries: Comparing different intervention types using meta-regression. Environ Sci Technol 43:8991-8997

Kennedy J, Ashmore J, Babister E, Kelman I (2008) The Meaning of 'Build Back Better': Evidence from Post-tsunami Aceh and Sri Lanka. Journal of Contingencies and Crisis Management 16(1):24-36

Kyessi AG (2005) Community-based urban water management in fringe neighbourhoods: the case of Dar es Salaam, Tanzania. Habitat International 29:1-25

Lawther PM (2009) Community involvement in post disaster re-construction Case study of the British Red Cross Maldives recovery program. Int I Strateg Prop Manag 13(2):153-169

Leon E, Kelman I, Kennedy J, Ashmore J (2009) Capacity building lessons from a decade of transitional settlement and shelter. Int I Strateg Prop Manag 13:247-265

Mintz E, Bartram J, Lochery P, Wegelin M (2001) Not just a drop in the bucket: Expanding access to point-of-use water treatment systems. Am J Public Health 92(10):1565-1570

Montalto F, Sheller M, Galada H, Gurian P, Piasecki M, Oconnor S (submitted) Transitions to Sustainable Sanitation Infrastructure in post-earthquake Leogane, Haiti: Including Stakeholder Preferences. Eng Stud

Organization for economic cooperation and development. http://www.oecd.org/ countries/haiti/

Peter-Varbanets M, Zurbrugg C, Swartz C, Pronk W (2009) Decentralized systems for potable water and the potential of membrane technology. Water Res 43:245-265

Schuller M, Morales P (ed) (2013) Tectonic Shifts: Haiti Since the Earthquake. Lynne Rienner Publishers, Boulder, CO

Sheller M, Galada HC, Montalto FA, Gurian PL, Piasecki M, Ayalew T, O'Connor S (2013) Women's Water and Sanitation Needs in Post-earthquake Leogane, Haiti. WH2O 2(1)

Sontag D (2012) In aiding quake-battered haiti, lofty hopes and hard truths. The New York Times, Print, December 23, 2012; http://www.nytimes.com/ 2012/12/24/world/americas/in-aiding-quake-batteredhaiti-lofty-hopes-andhard-truths.html

United States Environmental Protection Agency (1991) Design Manual: Alterantive Wastewater Collection Systems. In: EPA Office of Water. EPA Office of Research \& Development. EPA, Cincinnati, Ohio. 625/1-91/024. 220 pages

United Nations (2012) The Millennium Development Goals Report 2012. Accessed online at http://www.un.org/millenniumgoals/pdf/MDG\%20Report \%202012.pdf

Venhuizen D (1991) Decentralized Wastewater Management. Civ Eng 61(1):69. Retrieved October 6, 2010, from ABI/INFORM Global. (Document ID: 279650)

Wilderer PA, Schreff D (2000) Decentralized and centralized wastewater management: A challenge for technology developers. Water Sci Technol $41(1): 1-8$

Wolff G, Gleick PH (2002-2003) The Soft Path for Water. In: The World's Water. Island Press, Washington, D.C, pp 1-32

WHO and UNESCO (2005) Core questions on drinking-water and sanitation for household surveys. Available at http://www.who.int/water_sanitation_health/ monitoring/oms_brochure_core_questionsfinal24608.pdf Accessed on 10/4/13

doi:10.1186/2194-6434-1-5

Cite this article as: Galada et al:: Assessing preferences regarding centralized and decentralized water infrastructure in post-earthquake Leogane, Haiti. Earth Perspectives 2014 1:5 